\title{
COMMUNICATION BASED UPON ADVANCED RSS FEEDS CONCEPTS AND STRATEGIES
}

\author{
Peter J. A. Reusch ${ }^{1-2)}$, Bastian Stoll ${ }^{1)}$, Pawel Serwatowski ${ }^{1)}$ \\ ${ }^{1)}$ University of Applied Sciences - FH-Dortmund - Germany \\ ${ }^{2)}$ Peter.Reusch@FH-Dortmund.de, www.wirtschaft.fh-dortmund.de/reusch
}

\begin{abstract}
RSS feeds provide information through channels that can be subscribed. Updates in subscribed channels can be controlled by feed readers automatically - to make new information available to the user - immediately after the update. Today elementary RSS feeds are widely used for information dissemination. Advanced RSS concepts can improve communication concepts in many areas. A set of RSS applications is described, new perspectives are mentioned, and strategies derived from the implemented applications.
\end{abstract}

Keywords: RSS, Feeds, XML, Communication, Communication Strategies.

\section{INTRODUCTION}

RSS is a Web content syndication format. Its name is an acronym for Really Simple Syndication. All RSS files must conform to the XML 1.0 specification, as published by the World Wide Web Consortium (W3C $)^{1,2,3}$.

RSS is used to provide items containing short descriptions of web content together with a link to the source of this content. This information is delivered as an XML file called RSS feed, RSS stream, or RSS channel. The first online news site to use RSS feeds was Variety.com in June of $2002 .{ }^{4}$ News services, broadcasters, financial service providers and some others used RSS feeds first. In 2004 and 2005 RSS applications were implemented in many other organizations.

RSS feeds offer different kinds of news in specific channels. People interested in specific news subscribe such channels using feed readers that look for new contributions in these channels. The user can read these new contributions immediately after the update of the items in the channels.

In the future the technology of RSS feeds - or similar technologies - will become part of information systems everywhere. New communication concepts use RSS feeds to distribute classified news within organizations, within projects, and teams. Feedback functions will be added.

\footnotetext{
http://www.w3.org/

${ }^{2} \mathrm{http}: / /$ news.bbc.co.uk/rss/newsonline_uk_edition/world/rss091.xml

3 Ben Hammersley: Content Syndication with RSS, O'Reilly, 2003

${ }^{4} \mathrm{http}$ //en.wikipedia.org/wiki/Rss_feed
}

The role of RSS feeds in communication concepts has to be discussed in the future. Legal aspects and strategic aspects have to be considered.

\section{RSS FEEDS AT BBC}

Using RSS one can describe a channel with its items. Items include at least a title, a description and a link to a source with additional information about that channel. Figure 1 shows part of the channel of the BBC World News ${ }^{5}$ on the $29^{\text {th }}$ of December 2004 with the first two items, one about aid disposed to the victims of the tsunami in December 2004 in the Indian Ocean, and one about an explosion in Bagdad.

Figure 2 shows the same channel opened by a feed reader. The first item in the list of news the feed reader shows is titled "World boosts aid to wave victims". Figure 3 shows the corresponding website.

RSS feeds are used as news feeds worldwide (BBC, Yahoo ${ }^{6}$, Tagesschau, ... ). Dozens of feed readers are available to manage the RSS feeds ${ }^{7}$. Feed readers support the subscription of feeds and the access to the items in the feeds. Feed readers "watch" the feeds subscribed, detect updates of feeds and restore the links to the updated feeds.

Fundamental tools like the Internet Explorer and MS-Outlook can be expanded to manage RSS-feeds. In the future feed reader functions will be integrated in such tools. RSS feeds will be improved regarding

\footnotetext{
${ }^{5}$ http://news.bbc.co.uk/1/hi/help/3223484.stm?rss=http://

news.bbc.co.uk/rss/newsonline_uk_edition/front_page/rss091.xml

${ }^{6} \mathrm{http}: / /$ news.yahoo.com/

${ }^{7}$ http://www.feedreader.com/
} 
their functions and their integration into new communication concepts.

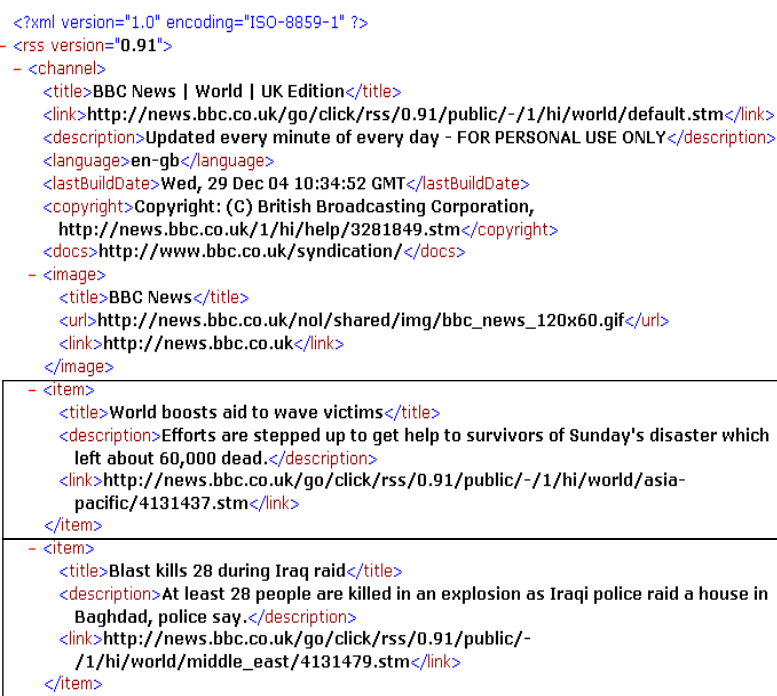

Fig. 1 - BBC World News RSS Channel on the 29th of December $2004^{8}$ - with only 2 selected items.

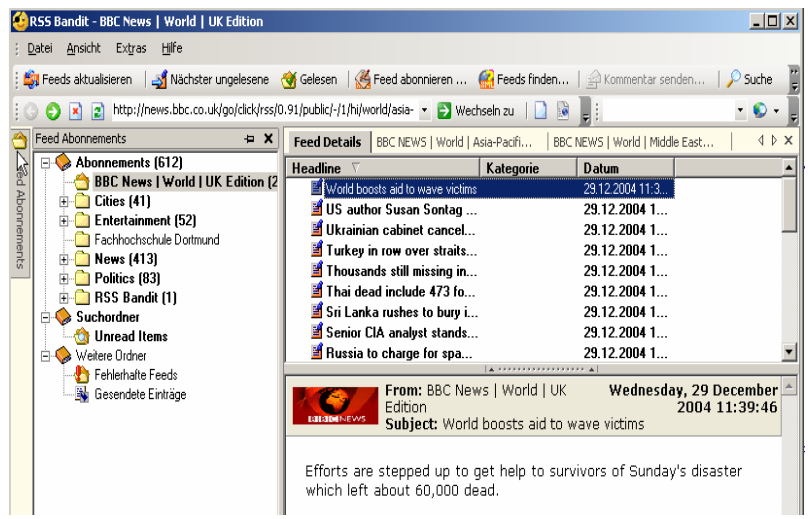

Fig. 2 - News feed of BBC World News represented by the RSSBANDIT $^{9}$ feed reader.

\section{B $B$ B CINEWS uк Еотrок}

Last Updated: Wednesday, 29 December, 2004, 09:42 GMT

E-mail this to a friend

븡 Printable version

\section{World boosts aid to wave victims}

Aid agencies and Western countries are stepping up efforts to help survivors of the Indian Ocean tsun disaster, which has killed about 60,000 people.

The US has more than doubled its pledge of funds to $\$ 35 \mathrm{~m}$. Two flotillas of US warships with 15,000 troops are carryin

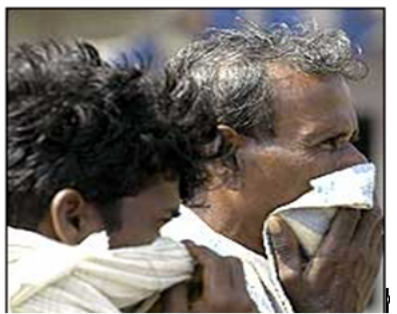

Fig. 3 - The document in the link element of the first item $^{10}$.

\section{NEW APPLICATIONS}

\footnotetext{
${ }^{8} \mathrm{http}: / /$ news.bbc.co.uk/rss/newsonline_uk_edition/world/rss091.xml

${ }^{9} \mathrm{http}: / /$ www.rssbandit.org/

${ }^{10} \mathrm{http}: / /$ news.bbc.co.uk/1/hi/world/asia-pacific/4131437.stm
}

The first public RSS application of the authors was implemented in 2003/2004 at the web site of the Faculty for Business Administration of the University of Applied Sciences in Dortmund to offer news for students on the rescheduling of courses. In case a lecture had been cancelled the students should know this as soon as possible.

The information on rescheduling and cancellations is available in a data base. The RSS feed is derived from the data base. The students can subscribe the feed with that kind of news.

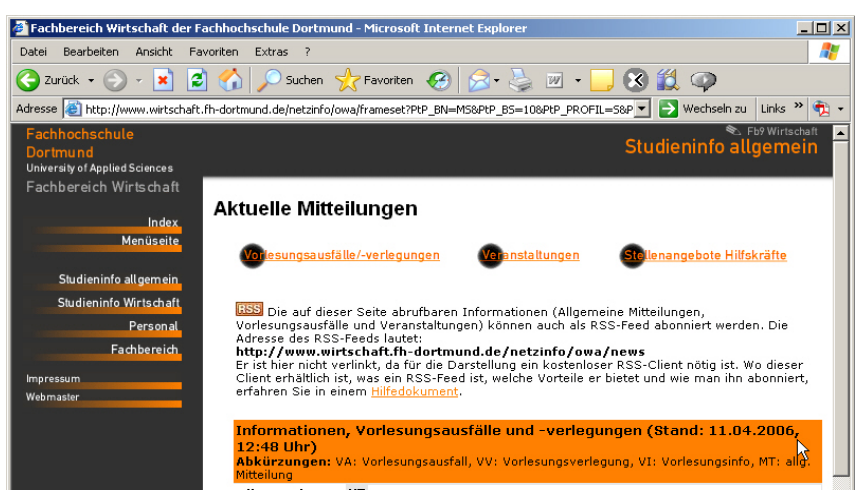

Fig. 4 - News feed at the Faculty of Business Administration at the University of Applied Sciences in Dortmund

Another RSS application was implemented at the web site of DEW - the local gas-, power and watersupplier in the area of Dortmund.

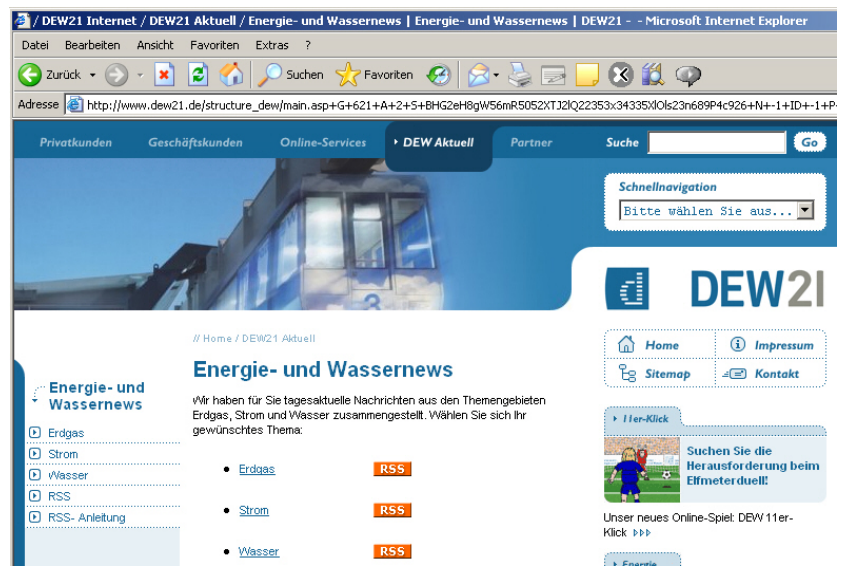

Fig. 5 - News feeds at DEW

In this case the RSS application offers additional channels for news - even world news - on gas, power and water. Again the information is available in a data base and the RSS feeds are derived from the data base.

So from the beginning the transformation of information from data bases was a core issue for the authors, and it was important to find an appropriate concept for the transformation. 
Going on with additional applications legal and strategic considerations became more and more important - as mentioned below. At the beginning we focused on standards and technologies.

\section{RSS STANDARDS}

There are several versions of RSS. The oldest widespread version of RSS is RSS 0.9, which was created by Dan Libby for the former "My Netscape" network in March 1999. The RSS 0.9 version was replaced in July 1999 by RSS 0.91 . The next step in the development of RSS was the version 0.92, which was released by UserLand. RSS 0.92 was an upgrade of RSS 0.91, where the numbers of items were extremely limited. The versions $0.9 \mathrm{x}$ are widespread and also called Rich Site Summary. ${ }^{11}$

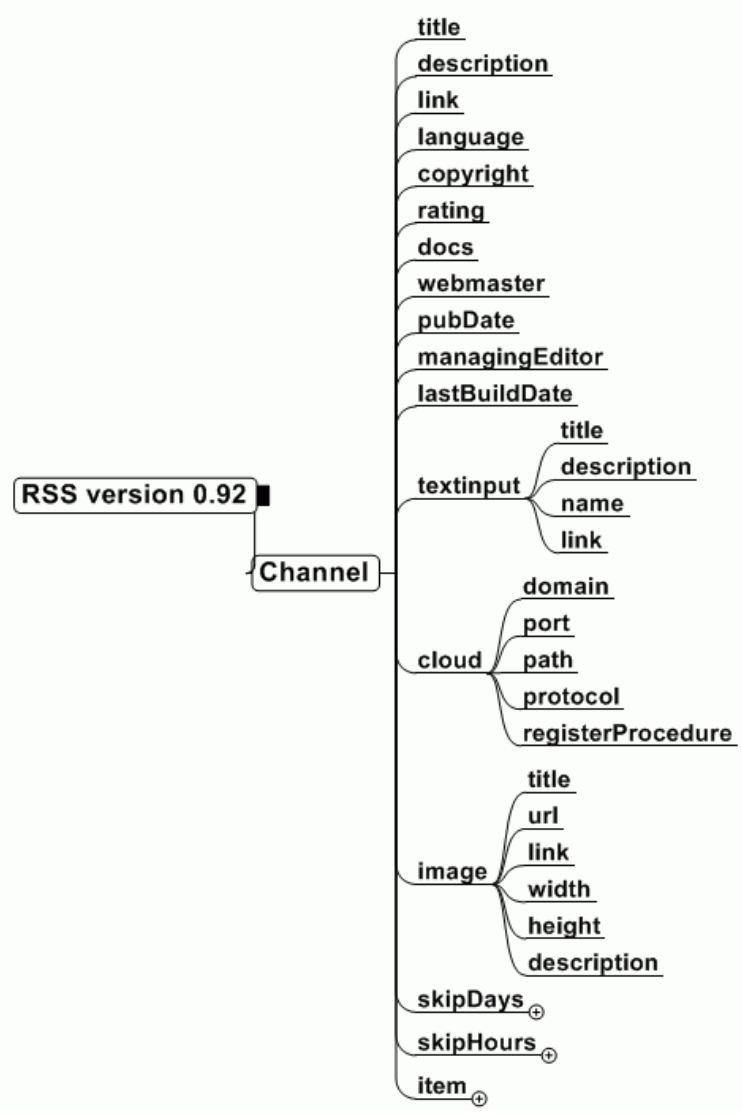

Fig. 6 - Structure of RSS 0.92 - Channel

The figure above shows the core structure of RSS channels according to RSS 0.92 . The figure bellow shows the details of the item-element.

Regarding the elements of the channel only "title", "link", and "description" are mandatory.

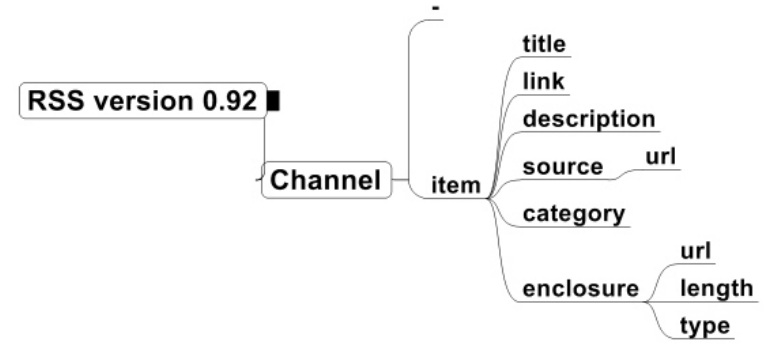

Fig. 7 - Structure of RSS 0.92 - Item

The version 2.0 of RSS extends the older RSS $0.9 \mathrm{x}$ specifications, but it does not use RDF - as RSS 1.0. RSS 2.0 is not downwards compatible to the $0.9 \mathrm{x}$ versions, but it is widely accepted as a quasi standard. The RSS 2.0 version is also called Really Simple Syndication.

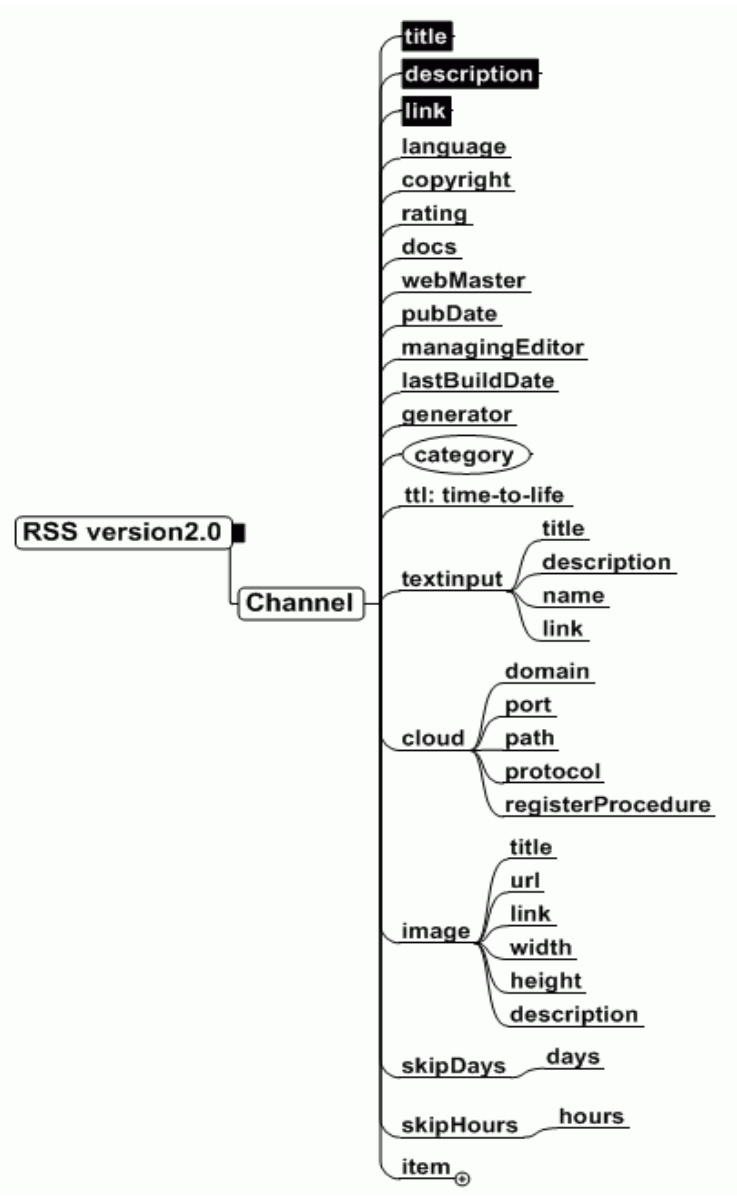

Fig. 8 - Structure of RSS 2.0 - Channel

RSS 2.0 was first developed as RSS 0.94; it was later renamed to 2.0. As the name RSS 0.94 indicates, this version is a successor of RSS 0.92. An important change of this version, in contrast to RSS 0.92 , is the usage of modules. This is similar to RSS 1.0 , but the modules of both versions are not compatible to each other. There are also some new

${ }^{11}$ http://en.wikipedia.org/wiki/RSS_\%28file_format $\% 29$ 
elements in this version of RSS, for example: "author", "comments" or "generator". 1213

The figures below show the core structure of RSS channels according to RSS 2.0. Again, only the channel-elements "title", "link", and "description" are mandatory.

Important for further application are the category-elements in the channel and in the items. That is the first step to provide and select channel and items based on classifications.

All applications implemented by the authors are based upon RSS 2.0.

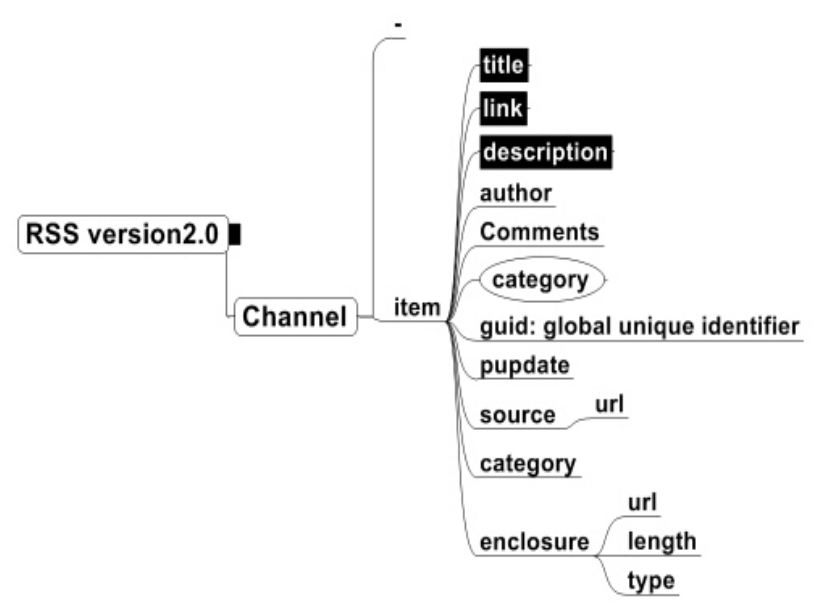

Fig. 9 - Structure of RSS 2.0 - Item

Now, the discussions on RSS 3.0 are open, but this version is not yet available. ${ }^{14}$

\section{XSL TRANSFORMATION FOR RSS FEEDS}

At the authors' institute RSS feeds for real business applications are partly derived by XSL transformations. This is a beneficial method especially when the sources are available in XML files. In one case RSS feeds for the local power and water supplier $\mathrm{DEW}^{15}$ were transformed from XML files of news providers.

Figure 10 shows that RSS feeds for the categories water, gas, and electricity at the DEW website are derived from the sources of the news provider by various XSL transformations.

Figure 11 shows part of the XSL transformation - the part where RSS items are created.

Figure 12 shows one item derived by this XSL transformation. This is part of the RSS feed at the DEW website for news that belong to the category water.

\footnotetext{
${ }^{12}$ Christoph Langguth: Neue Technologien in Internet und WWW, 2004

${ }^{13} \mathrm{http}: / / \mathrm{blogs}$.law.harvard.edu/tech/rss

${ }^{14}$ http://www.rss3.org/main.html

${ }^{15}$ www.dew.de
}

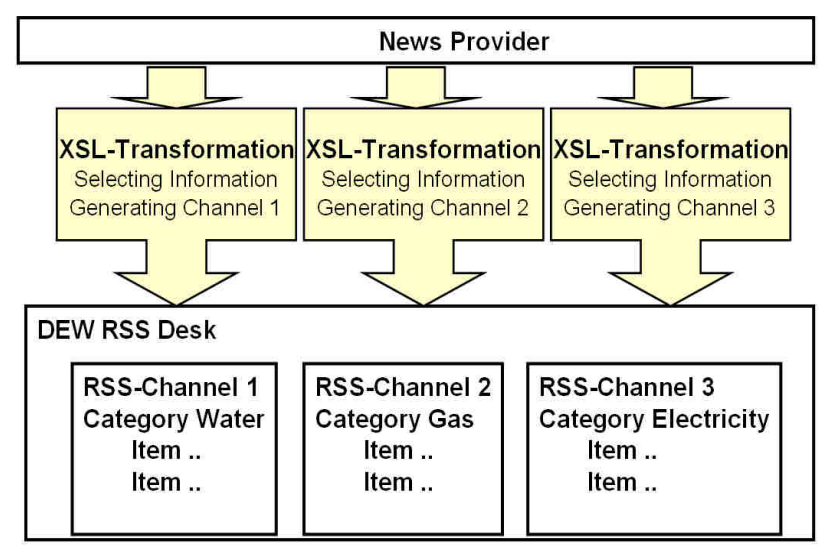

Fig.10 - XSL Transformations Build RSS Feeds.

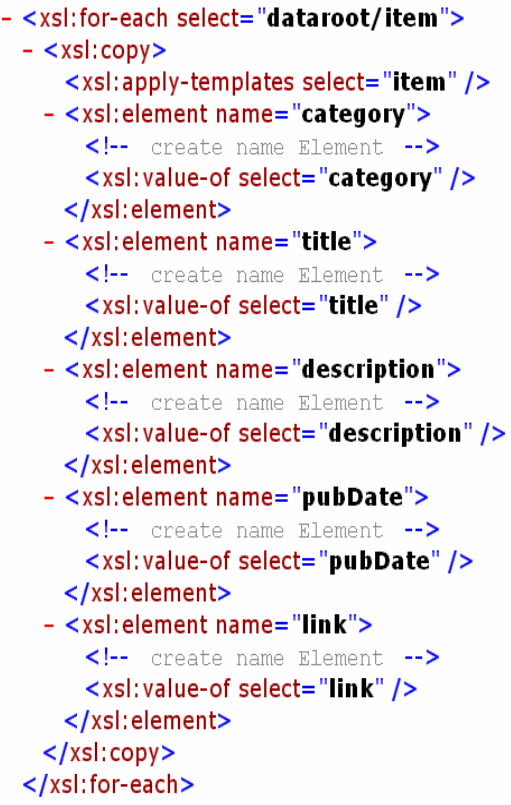

Fig.11 - XSL Transformation for RSS Feed

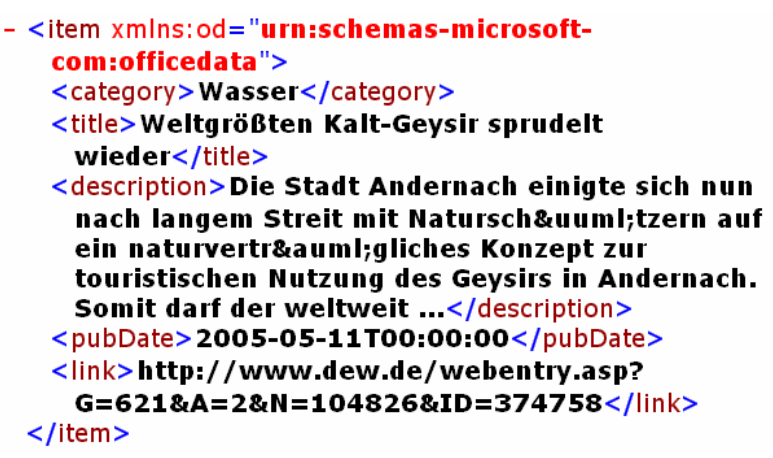

Fig.12 - Derived RSS Item for the RSS Feed

This kind of transformation will become increasingly important since the amount of XMLbased sources will grow and most database systems can create XML files. The selection of information for a channel can be done either by database export procedures or by the XSL transformation itself. The 
creation of all RSS channel and item elements should be done by the XSL transformation.

\section{FURTHER DEVELOPMENT}

Most feed readers available today are restricted to the required RSS channel elements and the required RSS item elements (title, link, description), and only a few more. Feedback elements of channels (textInput ) and elements to classify items or channels (category) and other elements that are optional according to the RSS-specification typically remain unused today. The following tables show part of the channel elements and all item elements according to RSS $2.0^{16}$

Table 1. RRS channel elements

\begin{tabular}{|c|c|}
\hline Channel-Element & Description \\
\hline title & The title of the channel \\
\hline link & $\begin{array}{l}\text { The URL to the website } \\
\text { corresponding to the channel }\end{array}$ \\
\hline description & $\begin{array}{l}\text { Phrase describing the } \\
\text { channel }\end{array}$ \\
\hline category & $\begin{array}{l}\text { Specifies one or more } \\
\text { categories that the channel } \\
\text { belongs to }\end{array}$ \\
\hline textInput & $\begin{array}{l}\text { Specifies a text input box } \\
\text { that can be displayed with } \\
\text { the channel }\end{array}$ \\
\hline
\end{tabular}

Table 2. RSS Item Elements

\begin{tabular}{|l|l|}
\hline Item-Element & Description \\
\hline title & The title of the item \\
\hline link & The URL of the item \\
\hline description & The item synopsis \\
\hline author & $\begin{array}{l}\text { Email address of the author of } \\
\text { the item }\end{array}$ \\
\hline category & $\begin{array}{l}\text { Includes the item in one or more } \\
\text { categories }\end{array}$ \\
\hline comment & $\begin{array}{l}\text { URL of a page for comments to } \\
\text { the item }\end{array}$ \\
\hline enclosure & $\begin{array}{l}\text { Describes a "media object" that } \\
\text { is attached to the item }\end{array}$ \\
\hline guid & $\begin{array}{l}\text { A string that uniquely identifies } \\
\text { the item }\end{array}$ \\
\hline pubDate & $\begin{array}{l}\text { Indicates when the item was } \\
\text { published }\end{array}$ \\
\hline source & $\begin{array}{l}\text { The RSS channel that the item } \\
\text { came from }\end{array}$ \\
\hline
\end{tabular}

The important category element is available at channel level and at item level. So the categories at item level can be organized as subcategories of channel categories.

The development of RSS feeds will go along the following steps:

\section{Elementary RSS feeds}

Today RSS feeds are offered on web sites and submit unclassified contents through feed channels. Feed channels that were found on any web sites or through search engines are subscribed. Subscribers apply simple feed readers to get updated channels and to read the items and further information.

\section{Advanced RSS feeds}

In the future RSS feeds will be offered on web sites and will submit categorised contents by using special RSS elements in feed channels. Feed channels will be subscribed. Subscribers will apply advanced feed readers to control the subscribed channels, to watch the items, to select items offered through the channel according to categories, and to give feedback to the provider or partner - using the standard textInput-element of RSS or new elements.

The areas of RSS applications will be expanded because new functions are available.

\section{Integrated Communication Concepts}

In the next step advanced RSS feeds will be integrated into new communication concepts for web-based communication. The integration of systems becomes more important than a poor dissemination of information. Feeds combine internal and external sources and improve work flows. An improved semantical representation will support the integration.

The following figure shows the structure of an advanced RSS application, based upon various kinds of sources, multi-level classification, and user interaction.

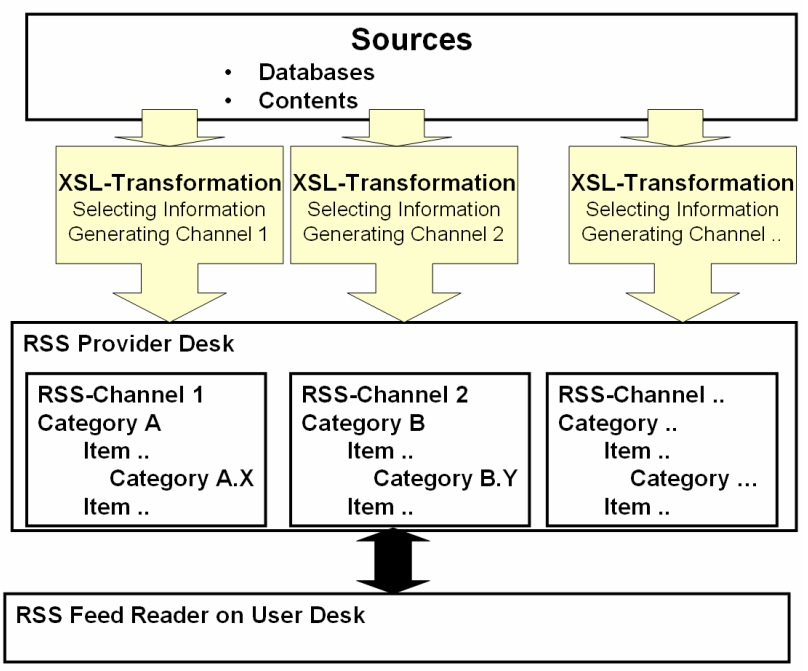

Fig. 13 - Interactive RSS with channels derived from different sources

\footnotetext{
${ }^{16} \mathrm{http} / / /$ blogs.law.harvard.edu/tech/rss\#hrelementsOfLtitemgt
} 


\section{NEXT STEPS}

At the authors' institute research and development on RSS is focused on following aspects:

- New RSS applications are built especially in areas without experience in RSS technologies so far, for example for power suppliers ${ }^{17}$ or institutes ${ }^{18}$. The experience derived from these projects is important for future communication concepts beyond those areas mentioned in the introduction.

- An advanced RSS application is built to support project management. Here a special classification of feed items is implemented. Information dissemination in a project is an important issue - and RSS channels can improve the dissemination of information and the transfer of information to other applications.

- To overcome some gaps in RSS feed readers XSL-style sheets are implemented to support the selection of items and the transfer of selected items to other applications. An integration of feeds and other applications is established.

The RSS application to support project management is based upon:

Channels for different kinds of stakeholders

- Project teams

- Departments, corporate groups, ...

- External partners of different types

- $\quad .$.

Items are classified according to

- International standards - processes and knowledge areas derived from the PMBOK $^{\circledR 19,20}$ of PMI $^{\circledR 21}$ for example, and the new concepts of OPM $3^{\circledR 22}$

- Standards of application systems - for example ASAP ${ }^{\circledR 23}$ with specific phases and tasks for $\mathrm{SAP}^{\mathbb{B} 24}$-projects

- Standards of special user groups like the VModel $^{25}$ for governmental projects in Germany

- Categories derived from tasks, resources and other elements of individual projects

- Organisational standards (work flow, phases, document types, ... )

- Importance, risk, ...

- ...

\footnotetext{
${ }^{17}$ for example at DEW in Dortmund

${ }^{18}$ for example at ECLASS Cologne

${ }^{19} \mathrm{http} / /$ www.pmi.org/prod/groups/public/documents/info/

pp pmbok2000welcome.asp

${ }^{20} \mathrm{http}$ ://www.pmibookstore.org/PMIBookStore/

productDetails.aspx? itemID $=358 \&$ varID $=1$

${ }^{21}$ www.pmi.org

22 www.pmi.org

${ }^{23} \mathrm{http}$ ://www.aasis.state.ar.us/Documentation/Archives/

impwrkplan.htm

${ }^{24}$ www.sap.com

${ }^{25}$ http://www.v-modell.iabg.de/kurzb/vm/b-vm.doc
}

This application is a prototype for advanced RSSapplications. Focused channels, classified items and new procedures to select and transfer information on an open XML platform improve the concepts of feeds, expand the functions of feed readers, and establish new communication concepts.

\section{STRATEGIC CONSIDERATIONS}

At the authors' institute we implemented several RSS applications. At the beginning we were focused on the technology. Then we had to discuss legal and strategic aspects more and more. We had to learn some lessons and we conclude our paper with some results.

The first implementation of RSS applications at the authors' institute were based upon very simple considerations, for example: RSS feeds can help students to get information on the rescheduling of courses immediately, and can they stay a home when a session has been cancelled.

In our first case the producer of the news and the provider of the feed were in the same organization and even the target group was part of the organization.

In the next practical application we introduced RSS feeds at the web site of the gas-, power- and water-supplier DEW. In this case the content of the feeds were news delivered by a third party - a news provider. With the RSS-feeds we added new channels for the transmission of information, that were already available before. We had to discuss the question: Is it allowed to offer this information in new channels. We have got the permission to do this.

In another case we supported the implementation of RSS feeds at the Ministry for Environment, Farming, and Transport in North-Rhine-Westfalia MUNLV. We were not allowed to make the link to the RSS feeds visible so far, becomes they wanted to start an overall discussion on communication strategies for the government of North-RhineWestfalia. So only insiders know that http://www.munlv.nrw.de/rss/munlv.xml there is the news feed:

There are some lessons we learned from our RSS-applications:

- Regarding the messages transmitted through RSS-feeds we have to consider: Who is the producer? Who is the owner? Who is the provider? And what is the destination?

- Do we have the right to transmit the messages?

- We have to consider the type of information we transmit through RSS-feeds: Is it a message that triggers actions at the 
destination? Is it a message that is nice to know? Or is it often really unimportant?

- We have to check what competing and supporting channels there are.

- We have to determine the time we provide information. And we have to determine the time we remove information from a feed.

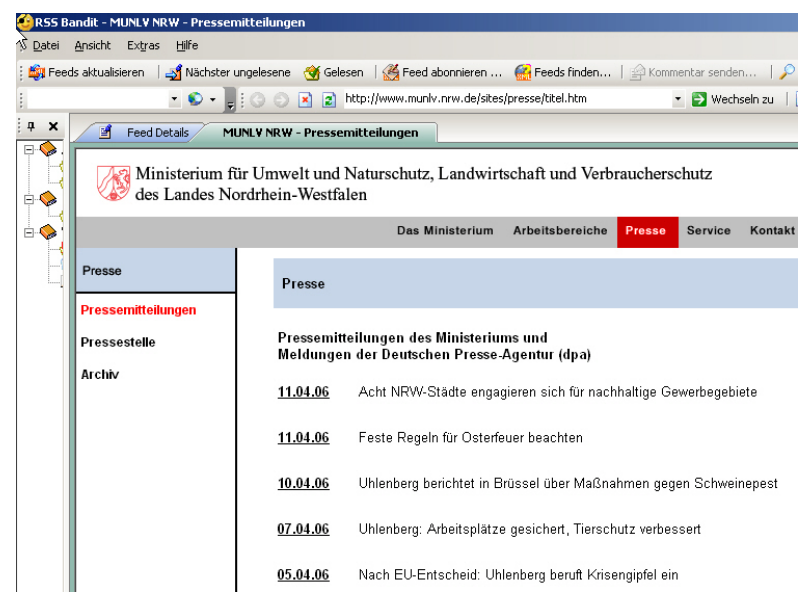

Fig. 14 - RSS-channel at MUNLV

\section{Strategical Considerations regarding RSS}

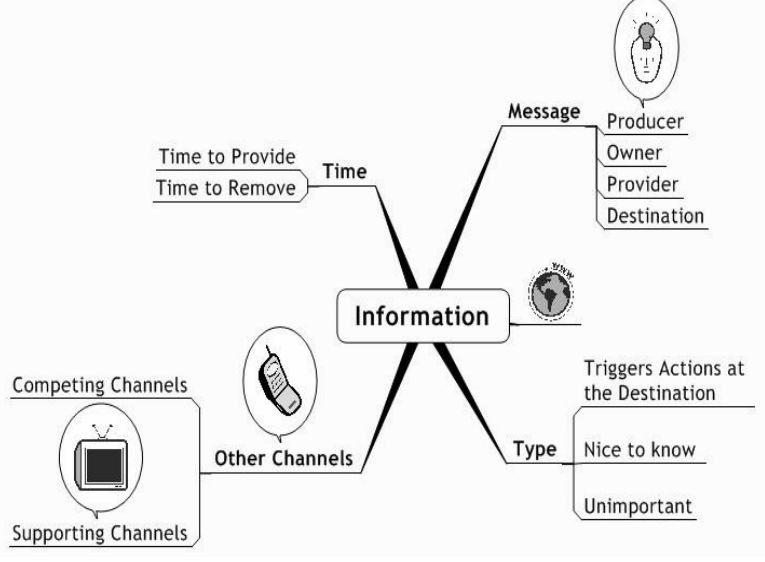

Fig. 15 - Strategic Considerations

And in the future we will have to focus more on the contents of messages:

- What kinds of news are provided, from which knowledge areas?

- Is there a classification of the content of messages? What kind of classification? Is there a free list of topics - like the BBClists? Is there a classification within a special interest group? Or is there a general standard - like $\mathrm{DDC}^{26}$ ?

- What filtering procedures are implemented by the user? Should the user follow his own perspectives? Should he follow standard classifications in order to collect message on subclasses?

\section{Strategical Considerations regarding RSS}

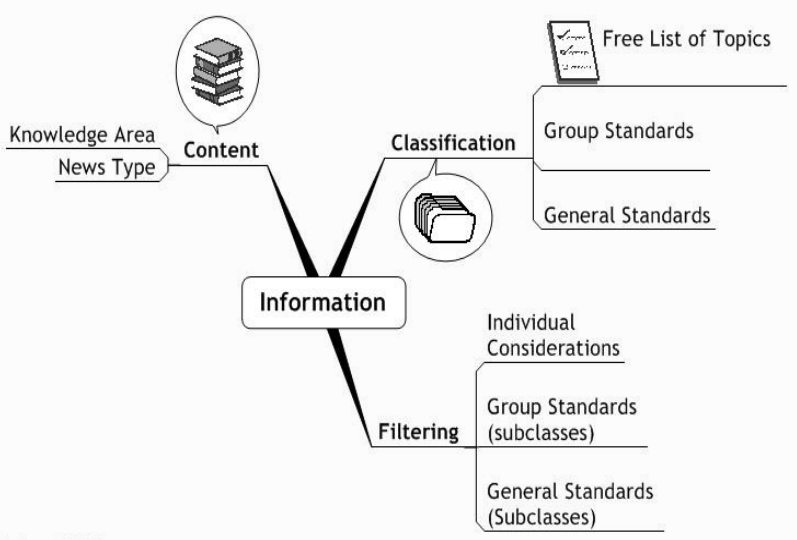

Fig. 16 - Strategic Considerations

\section{REFERENCES}

[1] Pawel Serwatowski. Aufbau von RSS Feeds zum Ausbau von Web-Applikationen am Beispiel der $D E W$, Diploma Thesis, Dortmund, 2005.

[2] Peter J. A Reusch, Bastian Stoll, Torsten Schulwandt, Pawel Serwatowski. New Communication Concepts based upon Advanced RSS-Feeds, Intelligent Data Acquisition and Advanced Computing Systems: IDAACS 2005.

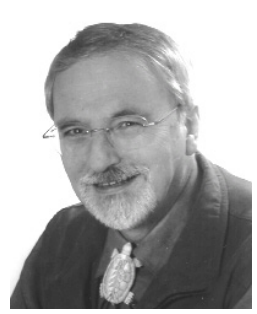

Peter J. A. Reusch

Born 1950. Graduated as Dr. rer. nat. at the University of Bonn 1976. Dr. h.c. of the State Economic University in Minsk and Dr. h.c. of the University of Lativia in Riga Professor at the University of Applied Sciences in Dortmund

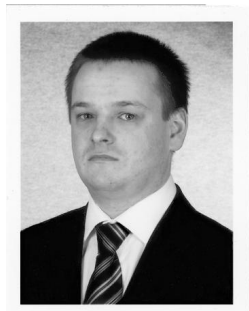

Pawel Serwatowski

Born 1977. Graduated as Magister Oec. at the University of Szczecin in Poland 2001 and Graduated as DiplomInformatiker (FH) at the University of Applied Sciences in Dortmund 2005

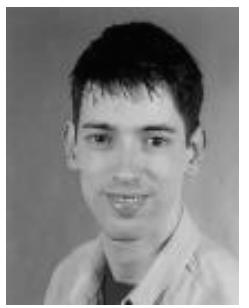

\section{Bastian Stoll}

Born 1977. Graduated as Diplom-Informatiker (FH) at the University of Applied Sciences in Dortmund 2004

\footnotetext{
${ }^{26}$ Dewey Decimal Classification: http://www.oclc.org/dewey/
} 